\title{
Avaliação pós-ocupação sob o aspecto do saneamento ambiental em área de interesse social urbanizada no município de Campina Grande, Paraíba
}

\author{
Post-occupancy evaluation with regard to the environmental sanitation \\ in an urbanized area of social concern in the municipality \\ of Campina Grande, Paraíba
}

Ricardo Nobrega Pedrosa', Lívia Izabel Bezerra de Miranda² , Márcia Maria Rios Ribeiro³

\section{RESUMO}

Nos últimos dez anos, o município de Campina Grande, Paraíba, foi beneficiado com inúmeros programas de urbanização em áreas de interesse social. Com a publicação da Lei no 11.445/2007 (Lei do Saneamento), dada a centralidade que o saneamento ambiental tem na vida das pessoas, é fundamental que processos de Avaliação Pós-Ocupação sejam procedidos. Esta pesquisa objetivou avaliar a infraestrutura de saneamento em área de interesse social sob diversos cenários de urbanização. O caso de estudo foi a comunidade Novo Horizonte, localizada na zona sul do município, por se tratar de uma área urbanizada com recursos do Orçamento Geral da União. Propõe-se uma metodologia para a aferição da salubridade ambiental, na qual é definido um Índice de Salubridade Ambiental para a comunidade Novo Horizonte, composto por sete indicadores relacionados com o saneamento ambiental, a saúde pública e aspectos socioeconômicos. Os resultados mostraram que a urbanização não ocorreu na amplitude desejada e que dentre os indicadores analisados houve destaque para o abastecimento de água e os resíduos sólidos, enquanto os relacionados aos aspectos socioeconômicos foram os que apresentaram os piores resultados dentre os cenários pesquisados. A pesquisa constatou quão nefasta é a execução de uma obra de urbanização segmentada no tempo, e realizada por empresas distintas, sobretudo quando os serviços de esgotamento sanitário são realizados em um primeiro instante. Conclui-se que a efetivação de avaliação pós-ocupacional é necessária para realimentar os projetos de urbanização em execução, ou a executar, quer seja com recursos públicos ou privados.

Palavras-chave: avaliação pós-ocupação; saneamento ambiental; habitação de interesse social; indicadores ambientais; gestão urbana.

\begin{abstract}
For the last ten years, the city of Campina Grande, Paraíba, has been benefited from a large number of urbanization programs of social concern. With the Federal Act 11,445/2007 (Sanitation Act), considering that environmental sanitation plays a central hole for the population, it is essential the development of Post-Occupancy Evaluation processes, This research aimed to evaluate the environmental performance of social interest under distinguished scenarios of urbanization. The Novo Horizonte community was chosen as case study, located in the southern part of the municipality, because the Federal government sponsored its urbanization process. A methodology for the assessment of environmental health is proposed, which is defined in one Index of Environmental Health for the community Novo Horizonte, composed of seven indicators related to environmental sanitation, public health and socioeconomic aspects. The results showed that urbanization did not occur at the desired amplitude. Among the analyzed indicators, the ones for the water supply and solid waste were more evident, while those related to socioeconomic factors were those that presented the worst results. This research showed how harmful is the execution of a work of segmented urbanization in time, and carried out by separate undertakings, especially when sewage services are done in the first instance. It is concluded that the effectiveness of occupational PostOccupancy Evaluation is needed to feedback the urbanization projects with funds from the public sector.
\end{abstract}

Keywords: post-occupancy evaluation; environmental sanitation; housing of social interest; environmental indicators; urban management. $\square$

'Engenheiro Civil. Mestre em Engenharia Civil e Ambiental pela Universidade Federal de Campina Grande (UFCG). Engenheiro Civil da Unidade Acadêmica de Engenharia Agrícola de Campina Grande - Campina Grande (PB), Brasil.

2Arquiteta e Urbanista. Doutorado em Desenvolvimento Urbano e Regional pela Universidade Federal de Pernambuco (UFPE). Professora Adjunta II da Unidade Acadêmica de Engenharia Civil da UFCG - Campina Grande (PB), Brasil.

3Engenheira Civil. Doutorado em Recursos Hídricos e Saneamento Ambiental pela Universidade Federal do Rio Grande do Sul (UFRGS). Professora Associada IV da Unidade Acadêmica de Engenharia Civil da UFCG - Campina Grande (PB), Brasil.

Endereço para correspondência: Ricardo Nobrega Pedrosa - Rua Coronel João da Costa e Silva, 369 - Bela Vista - 58428-735 - Campina Grande (PB). Brasil E-mail: ricardonpedrosa@gmail.com

Recebido: 19/02/15. Aceito: 11/O1/16. Reg. ABES: 146176 


\section{INTRODUÇÃO}

O crescente processo de urbanização tem afetado, de forma implacável e direta, a qualidade de vida da população e apresenta uma característica dominante que é a exacerbada propagação de favelas e similares. De acordo com Lima e Somekh (2013), essas aglomerações vêm fazendo, há mais de cinco décadas, parte do nosso contexto urbano, desafiando enormemente as políticas públicas nas diversas esferas de governo. $\mathrm{O}$ espaço urbano de moradia precária não se verifica, necessariamente, apenas na periferia das cidades, mas também nos cortiços das áreas centrais urbanas, e vêm nas últimas duas décadas disputando espaço com os condomínios fechados, shoppings centers, depósitos e portos secos (MARICATO, 2011).

Nos últimos dez anos, o município de Campina Grande, Paraíba, foi beneficiado com inúmeros programas de urbanização em áreas de interesse social, onde vultosos recursos públicos foram, e continuam sendo, investidos. Assegurar a moradia e a infraestrutura adequadas, bem como a segurança e a posse da terra, se destacam entre os objetivos desses programas. Para avaliar se esses benefícios têm promovido, efetivamente, qualidade de vida às pessoas, é fundamental que processos de Avaliação Pós-Ocupação (APO) sejam realizados nas áreas que estão sob intervenção no município, notadamente pelo fato de que a ocupação habitacional vem ocorrendo antes mesmo da conclusão de todas as etapas componentes do empreendimento e está causando, sistematicamente, problemas relacionados ao saneamento básico, ao controle urbano e à estrutura das edificações.

O país conta com um importante instrumento para assegurar melhores condições de habitabilidade, a Lei no 11.445/2007 (Lei do Saneamento), que estabelece as diretrizes nacionais para o saneamento básico, cujos "princípios fundamentais" se constituem em princípios que, se efetivamente observados, empreenderão um novo paradigma na habitação social. Dessa forma, os municípios brasileiros são solicitados a assumir competências quanto ao planejamento, à prestação, à regulação e à fiscalização dos serviços, para que, pragmaticamente, a universalização, a integralidade, a eficiência e a sustentabilidade econômica venham proporcionar uma gestão eficiente dos recursos hídricos.

De acordo com Nunes e Carissimi (2011), a partir da percepção de que a habitação é um problema que envolve toda a sociedade, a melhoria de sua qualidade, sobretudo as de interesse social, vem sendo debatida de forma abrangente em nosso país. A discussão brota naturalmente a partir do instante em que são vários os programas governamentais que tratam da problemática habitacional, coadunado ao fato dos elevados valores investidos e da consequente necessidade de dar transparência aos citados programas. Para Romero e Viana (2002), a avaliação dos conjuntos habitacionais implantados é uma necessidade que se impõe a partir do estado atual e deve ser feita analisando a interface do ponto de vista de habitação social, a satisfação dos beneficiários e as fortuitas demandas.

\section{O saneamento no Brasil e sua universalização}

Houve, inegavelmente, um avanço considerável no setor de saneamento no Brasil nas duas últimas décadas, com aporte expressivo de recursos financeiros. Mesmo assim, o nosso país apresenta números preocupantes no que diz respeito à universalização do acesso e à integralidade dos serviços de saneamento básico, que constituem exigências fundamentais da Lei $\mathrm{n}^{\circ} 11.445$, de 5 de janeiro de 2007, que estabeleceu as diretrizes nacionais para o saneamento básico, bem como para a política federal de saneamento básico.

Um aspecto fundamental abordado na Lei no 11.445 tem relação com as ações de planejamento, ao considerar que os planos de saneamento básico devem ser compatíveis com os planos das bacias hidrográficas em que estiverem inseridos. Relativamente à questão da integração entre política de recursos hídricos (Lei n9.433/97) e política de saneamento, a promulgação da Lei n- 11.445 impõe um desafio hercúleo, que é fazer caminhar solidariamente dois setores que, ao longo do tempo, pouco dialogaram em relação ao planejamento, até por conta de que as normas que regem as duas políticas são bastante distintas. A participação dos comitês de bacia hidrográfica na elaboração dos planos municipais de saneamento poderia ofertar uma colaboração inegável à parceria das citadas políticas (SENRA; MONTENEGRO, 2009).

A Lei $n^{\circ} 11.445$ estabelece, ainda, que a prestação dos serviços ofertados deve abranger, entre outros fundamentos, o diagnóstico da situação e de seus impactos nas condições de vida, utilizando sistema de indicadores sanitários, epidemiológicos, ambientais e socioeconômicos que apontem as causas das deficiências detectadas, bem como mecanismos e procedimentos para a avaliação sistemática da eficiência e eficácia das ações programadas.

Borja (2014) aponta que as dificuldades para a efetiva universalização do saneamento básico perpassam a dimensão política e ideológica, e alcança, entre outras, as dimensões "institucional, de financiamento, de gestão, da matriz tecnológica, da participação e controle social”. Os investimentos, sejam públicos ou privados, devem considerar também os aspectos sociais, de saúde e ambiental.

Libânio et al. (2005) evidenciam quão importante é discutir a gestão dos recursos hídricos com o setor de saneamento, já que as péssimas condições sanitárias constatadas em diversas bacias hidrográficas, ocupadas de forma desordenada, têm contribuído para a degradação da natureza e, por conseguinte, têm afetado os indicadores de saúde pública.

O saneamento básico guarda uma estreita e complexa relação com a saúde à medida que abrange variáveis culturais, sociais e econômicas, além das estritamente sanitárias. Não é fácil mensurar até que ponto o saneamento interfere na saúde da população, mas sabe-se que existe uma interface entre o saneamento e a saúde das pessoas. Nesse sentido, a Lei $n^{\circ}$ 11.445/07 se apoderou dos princípios do Sistema Único de Saúde (SUS) - universalidade e integralidade, em especial - e representa um instrumento indutor de promoção da saúde. O saneamento deve ser 
entendido não apenas como preventivo e controlador de doenças mas também como "instrumento de mudanças de atitude, hábitos e comportamentos para o alcance de um estilo de vida saudável" (SANTOS, 2009).

\section{Avaliação pós-ocupacional na perspectiva do saneamento ambiental}

O conceito de avaliação está relacionado à determinação do valor de alguma coisa, ao estabelecimento de que algo vale a pena. No campo da Engenharia e da Arquitetura, a avaliação está vinculada ao estabelecimento do valor da totalidade, ou de parte, do ambiente construído, ou à apreciação do processo de construção e seu gerenciamento. São várias as motivações determinantes de processo de avaliação, e este pode ser realizado para diferentes públicos, como clientes, engenheiros, arquitetos e usuários do ambiente construído. Os resultados de uma avaliação podem implicar em uma melhoria da qualidade de projetos e na construção e gestão do ambiente construído (VOORDT; WEGEN, 2005).

A avaliação é, portanto, um aspecto fundamental no ciclo de planejamento e da intervenção pública. Ela faculta oportunidades de reflexão crítica acerca dos resultados e impactos das obras, projetos e programas, além de propiciar, de forma densa, questionamentos sobre políticas públicas.

De forma pioneira no Brasil, Ornstein e Romero (1992) conceituaram a Avaliação Pós-Ocupacional (APO) como sendo uma metodologia que, tendo como referência parâmetros técnicos, funcionais, econômicos, entre outros, aliada à opinião de técnicos e usuários, possa diagnosticar um determinado ambiente construído sob perspectivas positivas e negativas, e propor recomendações que minimizem e/ou corrijam eventuais problemas detectados e realimentem o ciclo do processo de produção.

Kowaltowski et al. (2013), ao descreverem vários métodos e instrumentos de avaliação pós-ocupação voltados para a habitação de interesse social, ressaltaram que as avaliações devem ser focadas no aumento da qualidade da habitação, e que os moradores devem ter uma participação ativa em todas as etapas do processo construtivo, inclusive tendo acesso às possíveis avaliações - claras, transparentes, precisas e objetivas - que porventura venham a ser efetuadas.

Patel (2013) e Valladares (2013) consideraram fundamental a participação, na fase de concepção dos projetos de urbanização, dos usuários. Patel (2013) afirma que a urbanização de favelas, implementada a partir da participação da comunidade, é considerada a prática mais adequada para melhorar significativamente a vida de milhões de moradores de favelas. De fato, é inquestionável que a participação do usuário na origem do processo torna a avaliação pós-ocupação mais rica e dinâmica, até porque o usuário tem, efetivamente, um grau de corresponsabilidade no "sucesso/insucesso" do empreendimento.

Assim, a avaliação pós-ocupação pode ser utilizada, na perspectiva do saneamento ambiental, para verificar se a urbanização de uma favela promoveu a requalificação urbanística do ambiente e se os padrões de salubridade, relativamente aos recursos hídricos e à saúde dos moradores, estão condizentes com os padrões aceitáveis. A avaliação poderá fornecer subsídios aos gestores que lidam com o planejamento público, tornando mais ágeis as decisões a serem tomadas.

O desenvolvimento dessa pesquisa objetivou avaliar as condições de salubridade ambiental em uma área de interesse social urbanizada, no município de Campina Grande, Paraíba, observando se os requisitos, exigências e padrões de desempenho tecnológico previstos nos projetos seguiram os parâmetros adequados ao contexto regional, e fazer um estudo comparativo sob os diversos cenários da urbanização.

\section{METODOLOGIA}

\section{Área de estudo}

A Lei no 11.445/2007, art. 9, parágrafo I, ressalta que cabe ao titular dos serviços públicos elaborar os planos de saneamento básico e, no art. 49, parágrafo $\mathrm{X}$, menciona que a bacia hidrográfica deve ser adotada como unidade de referência para o planejamento de suas ações. Dessa forma, é pertinente contextualizar a localização da área a ser pesquisada (Figura 1).

A cidade de Campina Grande está localizada na região do médio curso do Rio Paraíba, bem próximo ao divisor da bacia hidrográfica, estando, portanto, submetida às especificidades peculiares da região, notadamente no que diz respeito à baixa precipitação concorrente para a recarga do reservatório que abastece a cidade.

A área avaliada foi a comunidade Novo Horizonte, localizada na região do Canal do Prado, na zona sul da cidade, nas imediações do Aeroporto João Suassuna e do distrito industrial, cuja ocupação se deu de forma irregular, na década de 1980. A motivação norteadora da escolha deveu-se ao fato de que, dentre todas as áreas em processo de urbanização no município de Campina Grande, com recursos do Orçamento Geral da União (OGU) e do Programa de Aceleração do Crescimento (PAC), é a única que teve o seu projeto inteiramente concluído, além de ser uma comunidade que padecia dos mais diversos problemas que a não urbanização acarretava: frequentes alagamentos, esgoto a céu aberto em todas as ruas, e resíduos sólidos acumulados em praticamente todos os locais (Figura 2).

\section{Obtenção de dados}

Os dados analisados foram coletados por meio de questionários respondidos pelos moradores da área objeto da pesquisa, cuja representatividade foi definida tomando por base procedimentos estatísticos, além dos disponibilizados pelos órgãos oficiais.

Em virtude de o caráter da pesquisa envolver dados obtidos a partir da percepção da população que habita o bairro do Novo Horizonte, foi elaborado um questionário com detalhes das especificidades dos indicadores considerados, pautado nas prescrições da Resolução n 466 , de 12 de dezembro de 2012, do Conselho Nacional de Saúde. O questionário elaborado, assim como o projeto de pesquisa, foi submetido 
ao Comitê de Ética em Pesquisa do Hospital Universitário Alcides Carneiro da Universidade Federal de Campina Grande e aprovado em junho de 2014.

\section{Período da pesquisa}

A pesquisa de campo com os moradores da comunidade Novo Horizonte foi realizada entre o final de maio e junho de 2014. Esse período coincide com a maior incidência pluviométrica na cidade de Campina Grande e, sob o ângulo dos questionamentos feitos aos moradores, é o mais indicado para a realização da pesquisa, tendo em vista que os problemas decorrentes das chuvas que assolam a região serviram de inspiração e justificativa para o processo de urbanização.

\section{Identificação dos indicadores, subindicadores e suas respectivas ponderações para a determinação do índice de salubridade ambiental}

A partir de pesquisas já realizadas (DIAS, 2003; BATISTA, 2005; MENEZES, 2007; SANTOS, 2013), foram identificados sete indicadores relacionados com a área de saneamento ambiental, de recursos hídricos, de saúde pública e socioeconômico. Conforme Brasil (2004), o conceito de salubridade ambiental "envolve os princípios da integralidade das ações (água, esgotos, resíduos sólidos, drenagem e controle de vetores) e da qualidade e quantidade dos serviços prestados, compreendendo o ambiente domiciliar (moradia) e o ambiente público (via)". Assim, os indicadores objeto dessa pesquisa são os seguintes:

1. $\mathrm{I}_{A A}$ - Indicador de Abastecimento de Água;

2. $\mathrm{I}_{E S}$ - Indicador de Esgotamento Sanitário;

3. $\mathrm{I}_{R S}$ - Indicador de Resíduos Sólidos;

4. $\mathrm{I}_{D U}$ - Indicador de Drenagem Urbana;

5. $\mathrm{I}_{S E}$ - Indicador Socioeconômico e Cultural;

6. $\mathrm{I}_{C M}$ - Indicador de Condições de Moradia; e

7. $\mathrm{I}_{C V}$ - Indicador de Controle de Vetores.

$\mathrm{O}$ índice de salubridade ambiental para a comunidade Novo Horizonte (ISA/NH) foi concebido tomando como referência os indicadores acima relacionados. Ele foi definido a partir de uma média ponderada dos indicadores, por meio da Equação 1:

$\mathrm{ISA} / \mathrm{NH}=\left(\mathrm{I}_{\mathrm{AA}} \times \mathrm{P}_{1}\right)+\left(\mathrm{I}_{\mathrm{ES}} \times \mathrm{P}_{2}\right)+\left(\mathrm{I}_{\mathrm{RS}} \times \mathrm{P}_{3}\right)+\left(\mathrm{I}_{\mathrm{DV}} \times \mathrm{P}_{4}\right)$

$+\left(\mathrm{I}_{\mathrm{SE}} \times \mathrm{P}_{5}\right)+\left(\mathrm{I}_{\mathrm{CM}} \times \mathrm{P}_{6}\right)+\left(\mathrm{I}_{\mathrm{CV}} \mathrm{PP}_{7}\right)$

Conforme sublinha Dias (2003), a discussão acerca de qual coeficiente adotar na ponderação é bastante polêmica. Nos vários estudos apontados na revisão de literatura, não houve uma discrepância significativa entre os coeficientes, ficando claro, entretanto, que a sua variação aponta resultados divergentes. A ponderação dos diversos indicadores

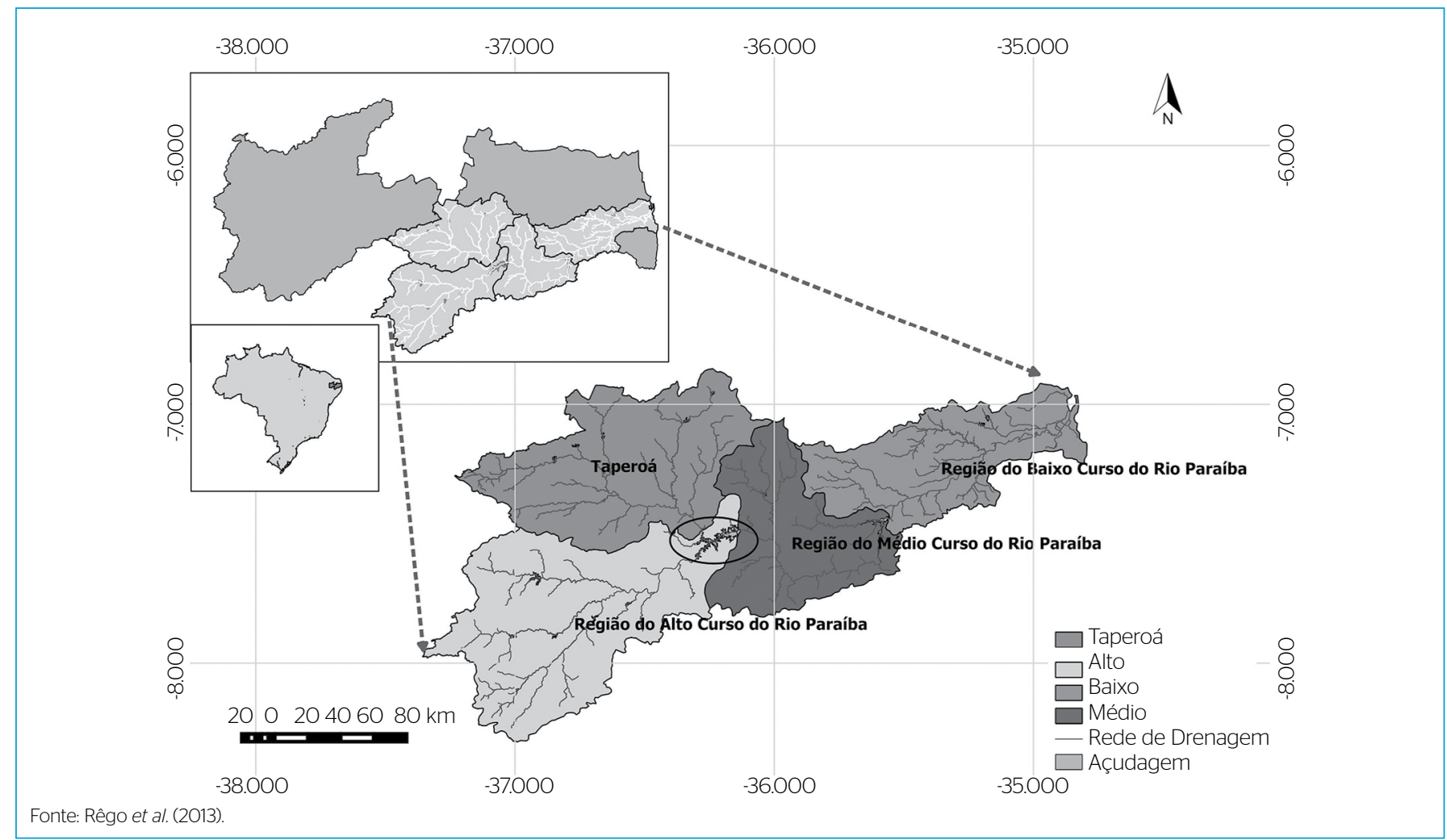

Figura 1 - Bacia hidrográfica do Rio Paraíba e suas subdivisões. 
foi definida a partir da proposta de Dias (2003) levando em consideração o grau de importância dos diversos componentes.

No Quadro 1 indicam-se as ponderações consideradas para os diversos componentes da fórmula estabelecida para o ISA/NH.

De maneira análoga ao que foi concebido relativamente aos indicadores, essa pesquisa também estabeleceu ponderadores para os subindicadores que fazem parte da fórmula que determina o índice de salubridade ambiental da comunidade Novo Horizonte (ISA/NH). As considerações efetuadas com relação aos indicadores, no que diz respeito aos critérios de ponderação, também têm valia para os subindicadores. Procurou-se enfatizar a ponderação em função do nível de importância dos subindicadores.

Para cada um dos subindicadores foram relacionadas circunstâncias que foram avaliadas a partir da atribuição de notas, que variavam de zero a dez. A nota máxima foi adjudicada para uma condição ótima da circunstância, e a nota mínima foi atribuída para uma situação de extremo desfavorecimento. As notas intermediárias foram atribuídas considerando uma escala de representatividade entre a pior e a melhor situação presenciada.
Os diversos subindicadores relacionados com os seus respectivos indicadores, bem como os pesos atribuídos e as notas das circunstâncias, encontram-se nos Quadros 2 a 8 . O índice de salubridade referente aos indicadores é determinado pela média ponderada do(s) subindicador(es), como descrito na fórmula:

$\mathrm{I}_{\text {Salubridade do Indicador }}=\sum_{1}^{\mathrm{N}}(\mathrm{P} \times \mathrm{NT}) \mathrm{I}_{\text {subindicador }}$

Em que:

$\mathrm{N}$ = número de subindicadores,

$\mathrm{P}=$ peso do subindicador $\mathrm{e}$

$\mathrm{NT}=$ nota atribuída à circunstância verificada

\section{Faixas de pontuação do Índice de Salubridade Ambiental da comunidade Novo Horizonte}

Em razão de esta avaliação se tratar de uma área urbanizada, foi adotada a pontuação proposta por Almeida (1999) para a classificação da salubridade, que é bem mais restritiva quanto aos padrões de salubridade do que
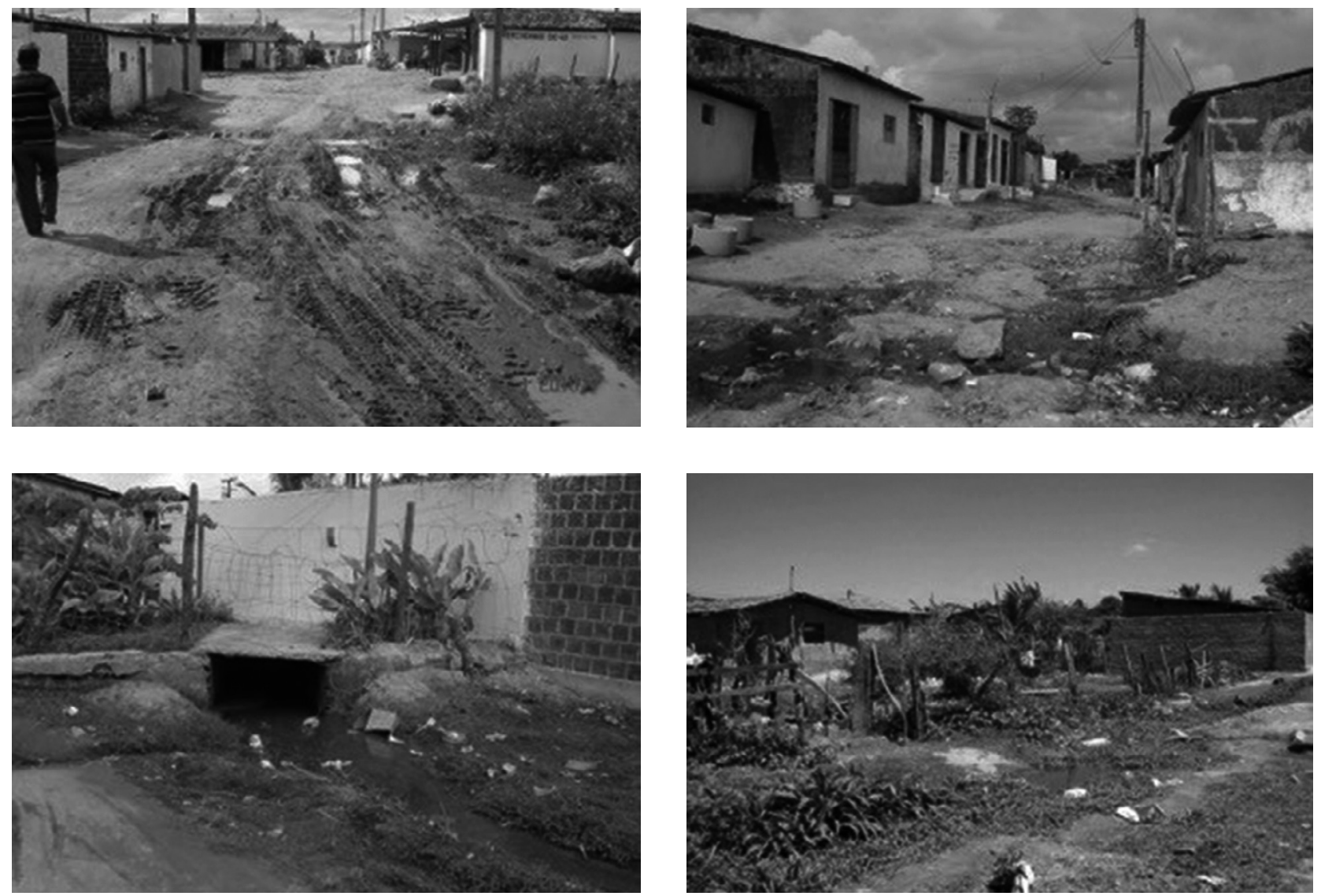

Figura 2 - Ruas da comunidade antes da urbanização. 
outras ponderações propostas (DIAS, 2003; BATISTA, 2005; MENEZES, 2007; SANTOS, 2013). De fato, é de se esperar que uma área avaliada um ano após a conclusão de um processo de urbanização, inclusive com um trabalho técnico social desenvolvido, durante e após a intervenção, oferte à população melhores condições de salubridade ambiental. No Quadro 9, apresenta-se a classificação que referenciou esta pesquisa.

\section{Caracterização dos cenários}

A área urbanizada na comunidade Novo Horizonte apresenta três cenários bem característicos quanto às intervenções: unidades habitacionais preservadas, unidades habitacionais que passaram por melhorias e unidades habitacionais tipo padrão.

O cenário das melhorias é composto pelas unidades habitacionais que sofreram intervenção física financiada com recursos do projeto de urbanização. As intervenções físicas, predominantemente, foram

Quadro 1 - Ponderação dos indicadores para o Índice de Salubridade Ambiental para a comunidade Novo Horizonte.

\begin{tabular}{|l|l|}
\multicolumn{1}{|c|}{ Componente } & \multicolumn{1}{c|}{ Ponderação } \\
\hline$I_{A A}$ - Indicador de Abastecimento de Água & $P_{1}=0,20$ \\
\hline$I_{E S}$ Indicador de Esgotamento Sanitário & $P_{2}=0,20$ \\
\hline$I_{R S}$ - Indicador de Resíduos Sólidos & $P_{3}=0,15$ \\
\hline$I_{D U}$ - Indicador de Drenagem Urbana & $P_{4}=0,10$ \\
\hline$I_{S E}-$ Indicador Socioeconômico e Cultural & $P_{5}=0,10$ \\
\hline$I_{C M}$ - Indicador de Condições de Moradia & $P_{6}=0,15$ \\
\hline$I_{C V}-$ Indicador de Controle de Vetores & $P_{7}=0,10$ \\
\hline
\end{tabular}

Fonte: Autor, adaptado de Dias (2003). voltadas para serviços de cobertura, revestimento de paredes e piso e, mais significativamente, para a construção de unidades sanitárias e acréscimo de um ambiente, que geralmente era um quarto.

O cenário tipo padrão é constituído por unidades habitacionais novas, tipo padrão, que foram construídas em terrenos desapropriados pela prefeitura de Campina Grande, localizados dentro da poligonal de urbanização. As famílias contempladas com essas unidades foram as que habitavam casas que tiveram que ser demolidas em função da configuração do projeto de urbanização.

As habitações que não se inserem nos cenários anteriores e que estão na poligonal de urbanização constituem o cenário de habitações preservadas.

Quadro 3 - Pesos e notas dos subindicadores do indicador de esgotamento sanitário.

\begin{tabular}{|c|c|c|c|}
\hline Subindicador & $\begin{array}{l}\text { Peso } \\
\text { (P) }\end{array}$ & $\begin{array}{l}\text { Circunstância } \\
\text { verificada }\end{array}$ & Nota (N) \\
\hline \multirow{5}{*}{ Águas Servidas $\left(I_{A S}\right)$} & \multirow{5}{*}{0,4} & Projeto de reúso & 10 \\
\hline & & Rede coletora de esgoto & 9 \\
\hline & & Fossa séptica + sumidouro & 8 \\
\hline & & Fossa séptica & 6 \\
\hline & & Solo, rio, sarjeta & $\mathrm{O}$ \\
\hline \multirow{4}{*}{ Dejetos Humanos $\left(I_{D H}\right)$} & \multirow{4}{*}{0,5} & Rede coletora & 10 \\
\hline & & Fossa séptica + sumidouro & 8 \\
\hline & & Fossa séptica & 6 \\
\hline & & Solo, rio, sarjeta & $\mathrm{O}$ \\
\hline \multirow{2}{*}{$\begin{array}{l}\text { Presença de cursos de } \\
\text { água mal cheirosos }\left(I_{R C}\right)\end{array}$} & \multirow{2}{*}{0,1} & $\operatorname{Sim}$ & 10 \\
\hline & & Não & 0 \\
\hline
\end{tabular}

Quadro 2 - Pesos e notas dos subindicadores do indicador de abastecimento de água.

\begin{tabular}{|c|c|c|c|}
\hline Subindicador & Peso (P) & Circunstância verificada & Nota (N) \\
\hline \multirow{2}{*}{ Origem do Abastecimento $\left(\mathrm{I}_{O A}\right)$} & \multirow{2}{*}{0,5} & Concessionária & 10 \\
\hline & & Poço ou fonte & O \\
\hline \multirow{7}{*}{ Condições de Instalação $\left(I_{A}\right)$} & \multirow{7}{*}{0,2} & Instalação interna à casa com reservatório sendo limpo periodicamente & 10 \\
\hline & & Instalação interna à casa com reservatório sem limpeza periódica & 08 \\
\hline & & $\begin{array}{l}\text { Instalação completa, sem reservatório, contando com peças mínimas (pia de } \\
\text { cozinha, tanque de lavar roupa, lavatório, chuveiro e bacia sanitária }\end{array}$ & 07 \\
\hline & & Instalação sem reservatório faltando até duas peças & 05 \\
\hline & & Instalação sem reservatório faltando mais que duas peças & $\mathrm{O} 4$ \\
\hline & & Apenas um ponto de água & $\mathrm{O} 3$ \\
\hline & & Sem instalação & O \\
\hline \multirow{3}{*}{ Frequência de Abastecimento $\left(\mathrm{I}_{\mathrm{AF}}\right)$} & \multirow{3}{*}{0,1} & Nunca falta água & 10 \\
\hline & & Falta água uma vez ao mês & 08 \\
\hline & & Mais de uma vez & 07 \\
\hline \multirow{2}{*}{$\begin{array}{l}\text { Conhecimento da Situação do Reservatório de } \\
\text { Abastecimento (ISR) }\end{array}$} & \multirow{2}{*}{0,05} & Sim & 10 \\
\hline & & Não & O \\
\hline \multirow{2}{*}{ Utilização de Método de Economia (IME) } & \multirow{2}{*}{0,15} & Sim & 10 \\
\hline & & Não & 0 \\
\hline
\end{tabular}


As unidades habitacionais, nesse caso, foram beneficiadas pelos serviços de pavimentação, esgotamento sanitário e drenagem implementados.

\section{Determinação da amostragem}

Tendo em vista o conhecimento da quantidade de unidades habitacionais da área urbanizada da comunidade Novo Horizonte, se tratando, pois, de uma população finita, Martins (2002) definiu a seguinte equação para a determinação do tamanho da amostra:

$\mathrm{n}=\frac{Z^{2} \cdot p \cdot q \cdot N}{d^{2}(N-1)+Z^{2} \cdot p \cdot q}$

Sendo:

$\mathrm{N}$ = número de valores que compõem uma população finita

$\mathrm{Z}=$ valor crítico correspondente ao grau de confiança desejado

$\mathrm{p}=$ proporção populacional de indivíduos que pertencem à categoria estudada

$\mathrm{q}$ = proporção populacional de indivíduos que não pertencem à categoria estudada

d = margem de erro ou erro máximo de estimativa.

No caso específico dessa pesquisa, optou-se por um intervalo de confiança de $90 \%$ e uma margem de erro de $10 \%$. Para esse grau de confiança, o valor crítico correspondente encontra-se tabelado e é igual a 1,645 . Como os valores amostrais p e q não são conhecidos, pode-se utilizar p e q como sendo igual a 0,5 .

A partir da identificação descrita no item 4.10, foi possível estabelecer o número de moradias dos diversos cenários e, assim, compor a amostragem, como indicado no Quadro 10.

As unidades habitacionais submetidas ao questionário foram escolhidas de forma aleatória, mediante sorteio. Ficou estabelecido que, em caso de resistência do(a) chefe da família em se submeter ao questionário, seria escolhida a casa imediatamente a esquerda e assim sucessivamente.

\section{Procedimento de análise do Índice de Salubridade Ambiental da comunidade Novo Horizonte}

O critério utilizado consistiu em interpretar as informações que foram tabuladas para cada um dos indicadores propostos e, logo após, criticar o índice de salubridade desse cenário.

Em um segundo momento, foram confrontados os desfechos dos três cenários característicos quanto às intervenções nas unidades habitacionais. Para essa apreciação foram assinalados os aspectos mais relevantes que os fizeram diferenciar-se uns dos outros; não foram discutidas as especificidades relativas a cada um dos subindicadores, como procedido em relação ao cenário descrito no parágrafo precedente. Em ambas as apreciações foi dada ênfase a se examinar se os requisitos, as exigências e os padrões tecnológicos previstos nos diversos projetos foram competente e prudentemente observados.

No questionário respondido pelo(a) a(o) chefe da família houve a indagação sobre a qualidade dos serviços de abastecimento de água, esgotamento
Quadro 4 - Pesos e notas dos subindicadores do indicador de resíduos sólidos.

\begin{tabular}{|c|c|c|c|}
\hline Subindicador & $\begin{array}{l}\text { Peso } \\
(P)\end{array}$ & Circunstância verificada & $\begin{array}{l}\text { Nota } \\
(\mathrm{N})\end{array}$ \\
\hline \multirow{3}{*}{$\begin{array}{l}\text { Acondicionamento } \\
\text { na Edificação }\left(\left.\right|_{\mathrm{AE}}\right)\end{array}$} & \multirow{3}{*}{0,4} & $\begin{array}{l}\text { Recipiente fechado ou } \\
\text { saco plástico fechado }\end{array}$ & 10 \\
\hline & & $\begin{array}{l}\text { Recipiente aberto ou } \\
\text { saco plástico aberto }\end{array}$ & 6 \\
\hline & & Não acondicionado & 0 \\
\hline \multirow{5}{*}{$\begin{array}{l}\text { Recolhimento } \\
\left.\text { dos Resíduos (I }\left.\right|_{R R}\right)\end{array}$} & \multirow{5}{*}{0,4} & Coleta seletiva & 10 \\
\hline & & Coleta pública diária & 9 \\
\hline & & Coleta pública alternada & 8 \\
\hline & & Queima & 6 \\
\hline & & $\begin{array}{l}\text { Disposição aleatória/ } \\
\text { terrenos baldios/córregos }\end{array}$ & 0 \\
\hline \multirow{2}{*}{$\begin{array}{l}\text { Regularidade na } \\
\text { Varrição }\left(I_{\mathrm{RV}}\right)\end{array}$} & \multirow{2}{*}{0,1} & Existe & 10 \\
\hline & & Não existe & $\mathrm{O}$ \\
\hline \multirow{2}{*}{ Lixo em Terrenos Próximos } & \multirow{2}{*}{0,1} & Não existe & 10 \\
\hline & & Existe & 0 \\
\hline
\end{tabular}

Quadro5-Pesos e notas dos subindicadores do indicador de drenagem.

$\left.\begin{array}{|l|c|c|c|}\text { Subindicador } & \begin{array}{c}\text { Peso } \\ (\mathrm{P})\end{array} & \begin{array}{c}\text { Circunstância verificada } \\ \text { Ocorrência de Inundação }\end{array} & \multirow{2}{*}{\begin{array}{c}\text { Nota } \\ \text { (N) }\end{array}} \\ \hline \text { no Domicílio }\left(\mathrm{I}_{\mathrm{OA}}\right)\end{array}\right)$

Quadro 6 - Pesos e notas dos subindicadores do indicador socioeconômico e cultural.

\begin{tabular}{|c|c|c|c|}
\hline Subindicador & $\begin{array}{l}\text { Peso } \\
(\mathrm{P})\end{array}$ & Circunstância verificada & $\begin{array}{l}\text { Nota } \\
\text { (N) }\end{array}$ \\
\hline \multirow{2}{*}{ Renda Familiar $\left(\mathrm{I}_{\mathrm{RF}}\right)$} & \multirow{2}{*}{0,5} & Maior que $1 / 2 \mathrm{SM}$ & 10 \\
\hline & & Menor que $1 / 2 \mathrm{SM}$ & 0 \\
\hline \multirow{2}{*}{$\begin{array}{l}\text { Titularidade da } \\
\text { residência }\left(\left.\right|_{T R}\right)\end{array}$} & \multirow{2}{*}{0,2} & Possui & 10 \\
\hline & & Não possui & $\mathrm{O}$ \\
\hline \multirow{6}{*}{$\begin{array}{l}\text { Escolaridade do(a) chefe } \\
\text { da família }\left(\left.\right|_{E F}\right)\end{array}$} & \multirow{6}{*}{0,3} & $\begin{array}{l}\text { Superior (completo } \\
\text { ou incompleto) }\end{array}$ & 10 \\
\hline & & Médio completo & 8 \\
\hline & & Médio incompleto & 7 \\
\hline & & Fundamental completo & 6 \\
\hline & & Fundamental incompleto & 4 \\
\hline & & Analfabeto & 0 \\
\hline
\end{tabular}

SM: Salário mínimo. 
Quadro 7 - Pesos e notas dos subindicadores do indicador condições de moradia.

\begin{tabular}{|c|c|c|c|c|}
\hline Subindicador & $\begin{array}{l}\text { Peso } \\
(\mathrm{P})\end{array}$ & \multicolumn{2}{|c|}{ Circunstância verificada/peso $\left(p_{n}\right)$} & $\begin{array}{l}\text { Nota } \\
(\mathrm{N})\end{array}$ \\
\hline \multirow{26}{*}{$\begin{array}{l}\text { Tipologia } \\
\text { Construtiva } \\
\left(\mathrm{I}_{\mathrm{RF}}\right)\end{array}$} & \multirow{26}{*}{0,5} & \multirow{2}{*}{$\begin{array}{l}\text { Cobertura } \\
\left(\mathrm{I}_{\mathrm{CB}}\right) / 0,1\end{array}$} & $\begin{array}{l}\text { Material durável } \\
\text { (telha cerâmica, } \\
\text { fibrocimento, } \\
\text { alumínio, laje) }\end{array}$ & 10 \\
\hline & & & $\begin{array}{l}\text { Material não durável } \\
\text { (zinco, madeira } \\
\text { aproveitada, palha) }\end{array}$ & $\mathrm{O}$ \\
\hline & & \multirow[t]{2}{*}{$\begin{array}{l}\text { Paredes } \\
\left(\mathrm{I}_{\mathrm{PA}}\right) / 0,1\end{array}$} & $\begin{array}{l}\text { Material durável } \\
\text { (alvenaria de tijolos, } \\
\text { pedra, adobe, } \\
\text { concreto, taipa } \\
\text { revestida, madeira } \\
\text { aparelhada }\end{array}$ & 10 \\
\hline & & & $\begin{array}{c}\text { Material não durável } \\
\text { (taipa não revestida, } \\
\text { madeira aproveitada, } \\
\text { palha) }\end{array}$ & $\mathrm{O}$ \\
\hline & & \multirow{8}{*}{$\begin{array}{c}\text { Revestimento } \\
\text { das paredes } \\
\text { (ambiente } \\
\text { seco) }\left(I_{A S}\right) / 0,1\end{array}$} & Cerâmica & 10 \\
\hline & & & Reboco com pintura & 9 \\
\hline & & & $\begin{array}{l}\text { Reboco e pintura } \\
\text { com cal }\end{array}$ & 8 \\
\hline & & & Reboco sem pintura & 7 \\
\hline & & & Chapisco com pintura & 6 \\
\hline & & & Chapisco sem pintura & 5 \\
\hline & & & Parede crua & 4 \\
\hline & & & Taipa & $\mathrm{O}$ \\
\hline & & \multirow{8}{*}{$\begin{array}{c}\text { Revestimento } \\
\text { das paredes } \\
\text { (ambiente } \\
\text { molhado) } \\
\left(\mathrm{I}_{\mathrm{AM}}\right) / 0,1\end{array}$} & Cerâmica & 10 \\
\hline & & & Reboco com pintura & 9 \\
\hline & & & $\begin{array}{l}\text { Reboco e pintura } \\
\text { com cal }\end{array}$ & 8 \\
\hline & & & Reboco sem pintura & 7 \\
\hline & & & Chapisco com pintura & 6 \\
\hline & & & Chapisco sem pintura & 5 \\
\hline & & & Parede crua & 4 \\
\hline & & & Taipa & 0 \\
\hline & & \multirow{6}{*}{$\begin{array}{l}\text { Revestimento } \\
\text { do piso }\left(I_{R P}\right) / O, 1\end{array}$} & Cerâmica & 10 \\
\hline & & & Cimentado queimado & 8 \\
\hline & & & Cerâmica porosa & 7 \\
\hline & & & Cimentado grosso & 6 \\
\hline & & & $\begin{array}{l}\text { Laje de pedra } \\
\text { ou tijolo batido }\end{array}$ & 5 \\
\hline & & & Sem revestimento & 0 \\
\hline \multirow{5}{*}{$\begin{array}{l}\text { Conservação } \\
\left(\left.\right|_{C S}\right)\end{array}$} & \multirow{5}{*}{0,5} & & Ótimo & 10 \\
\hline & & & Bom & 8 \\
\hline & & & Regular & 7 \\
\hline & & & Precário & 4 \\
\hline & & & Péssimo & 0 \\
\hline
\end{tabular}

sanitário, coleta de resíduos sólidos e drenagem urbana, que representam aproximadamente 2/3 da ponderação do ISA/NH. Essas observações efetuadas também serviram de balizamento para a análise e discussão, sendo extremamente importantes para privilegiar a avaliação a partir do ponto de vista do usuário, como propõe a literatura que versa sobre a avaliação pós-ocupação.

\section{RESULTADOS E DISCUSSÃO}

\section{Indicador de Abastecimento de Água}

A partir da percepção dos moradores, o abastecimento de água teve uma avaliação entre ótimo e bom; de 68,34\%, 26,67\% consideraram o serviço como regular e apenas $5 \%$ consideraram o abastecimento como sendo precário ou péssimo. O serviço poderia ser mais bem avaliado pelos usuários caso a concessionária de água e esgoto fosse mais ágil quanto ao concerto de vazamentos, bem como no que se refere ao fornecimento da água, diminuindo o período de desabastecimento. É oportuno considerar que essa insatisfação manifestada tende a aumentar caso ocorra um provável episódio de racionamento de água.

Os resultados obtidos a partir dos subindicadores indicaram uma boa performance do abastecimento de água quanto à salubridade ambiental, sendo enquadrada como salubre, ou de salubridade moderada, pela totalidade das unidades habitacionais.

O volume do reservatório que abastece a cidade de Campina Grande vem diminuindo consideravelmente e demandou um processo de racionamento que acarretará, particularmente na comunidade urbanizada, uma condição de extrema dificuldade, já que a área praticamente não dispõe de capacidade de reservação instalada. Certamente, o racionamento aumentará a susceptibilidade de ocorrência de doenças na medida em que haverá uma redução de práticas higiênicas salutares que dependem exclusivamente da água.

\section{Indicador de Esgotamento Sanitário}

Do ponto de vista dos moradores, existe um patente descontentamento quanto a esse indicador, que pode ser justificado pelo hiato temporal suficientemente grande, cerca de aproximadamente três anos, entre a conclusão da rede de esgotamento sanitário e a pavimentação em paralelepípedo, ocasionando vários incidentes de obstrução dos poços de visita, assim como pelo não acompanhamento dos serviços por parte da concessionária de água e esgoto.

Outro aspecto, por demais considerável, é o de que a rede de drenagem urbana apresenta uma grande concentração de dejetos sanitários, como mostrado na Tabela 1. Os dados obtidos se constituem em um claro indicativo da existência de ligações furtivas na rede de drenagem, advindas dos esgotos residenciais e das pequenas indústrias localizadas na área urbanizada.

Os resultados obtidos a partir dos subindicadores indicaram que o índice de salubridade foi de $91,67 \%$, enquanto $43,34 \%$ dos usuários consideraram o serviço como precário e péssimo. Essa discrepância pode ser justificada por conta dos constantes e variados problemas que 
têm ocorrido, com ênfase para as obstruções dos poços de visita e a demora na solução destas por parte da concessionária.

\section{Indicador de Resíduos Sólidos}

Esse indicador, a partir dos questionamentos objetivos submetidos pela pesquisa, foi considerado moderadamente salubre por $100 \%$ dos moradores. Foi procedida uma simulação no caso de a varrição vir a ser feita pelo poder público e, caso essa salutar prática viesse a ser adotada, a área seria enquadrada como salubre por $95 \%$ dos moradores, o que, sem dúvida, seria um índice bastante satisfatório. Não houve registro de nenhum episódio de coleta seletiva, o que pode ser justificado pela

Quadro 8 - Peso e notas do subindicador de controle de vetores.

\begin{tabular}{|l|c|c|c|}
\hline Subindicador & Peso (P) & Circunstância verificada & Nota (N) \\
\hline $\begin{array}{l}\text { Ocorrência de } \\
\text { Doenças* }\left(I_{O D}\right)\end{array}$ & 1 & Ocorreu & 10 \\
\cline { 3 - 4 } & & Não ocorreu & 9 \\
\hline
\end{tabular}

* Doenças (dengue, febre amarela, doença de Chagas, leishmaniose, esquitossomose) transmitidas por vetores no último ano, pelo menos uma vez.

Quadro 9 - Pontuação referencial do nível de salubridade.

\begin{tabular}{|l|c|}
\hline Situação de salubridade & Pontuação \\
\hline Salubre & $8,5<1 \leq 10,0$ \\
\hline Salubridade moderada & $7,0 \leq 1 \leq 8,5$ \\
\hline Salubridade insastifatória & $1<7,0$ \\
\hline
\end{tabular}

Fonte: Autor, adaptado de Almeida (1999).

Quadro 10 - Número de unidades habitacionais e amostra dos diversos cenários.

\begin{tabular}{|l|c|c|}
\hline Cenário & Unidades habitacionais & Amostra \\
\hline Melhorias & 110 & 43 \\
\hline Unidade habitacional tipo padrão & 69 & 35 \\
\hline Unidade habitacional preservada & 320 & 57 \\
\hline Área urbanizada & 499 & 60 \\
\hline Inicial & 499 & 60 \\
\hline
\end{tabular}

Tabela 1 - Indicadores referenciais para a caracterização da presença de esgoto.

\begin{tabular}{l|c|c|c|c} 
& \multirow{2}{*}{ Indicadores analisados } & Resultados & \multicolumn{3}{|c}{ Valores referenciais (mg/L) } \\
\cline { 3 - 6 } & & $\begin{array}{c}\text { Esgoto } \\
\text { forte }\end{array}$ & $\begin{array}{c}\text { Esgoto } \\
\text { médio }\end{array}$ & $\begin{array}{c}\text { Esgoto } \\
\text { fraco }\end{array}$ \\
\hline Oxigênio dissolvido & $0,20 \mathrm{mg} / \mathrm{L}$ & 0 & 0 & 0 \\
\hline DBO & $181,0 \mathrm{mg} / \mathrm{L}$ & 400 & 200 & 100 \\
\hline DQO & $747 \mathrm{mg} / \mathrm{L}$ & 800 & 400 & 200 \\
\hline Sólidos suspensos totais & $484,0 \mathrm{mg} / \mathrm{L}$ & 360 & 230 & 120 \\
\hline Sólidos suspensos voláteis & $242,67 \mathrm{mg} / \mathrm{L}$ & 280 & 175 & 90 \\
\hline Sólidos suspensos fixos & $241,33 \mathrm{mg} / \mathrm{L}$ & 80 & 55 & 30 \\
\hline
\end{tabular}

DBO: Demanda Bioquímica de Oxigênio; DQO: Demanda Química de Oxigênio. Fonte: Adaptado a partir de Jordão, E.P.; Pessôa, C.A. (2009). ineficiência do poder público municipal em implementar uma política de resíduos sólidos que contemple essa coleta em todo o município.

A área urbanizada, sob o julgamento dos moradores, foi bem avaliada, já que $96,67 \%$ consideraram os serviços como ótimo ou bom, enquanto $3,33 \%$ avaliaram os serviços como regulares.

$\mathrm{O}$ aspecto inerente aos resíduos sólidos em terrenos próximos às moradias só foi confirmado por apenas $5 \%$ das unidades pesquisadas, que se constitui em um excelente indicador se comparado com a maioria dos bairros do município, que apresentam, em diversos lotes urbanos, depósitos irregulares de resíduos sólidos, inclusive na área central da cidade, se constituindo em um tema recorrentemente abordado pela mídia a partir das constantes reclamações dos cidadãos. O fato da existência de poucos "pontos de resíduos sólidos", sem dúvida, é fundamental para evitar a disseminação de vetores e também pelo fato de contribuir para que o recolhimento desses resíduos sólidos se dê de forma mais célere pelo poder público, que, no caso do município de Campina Grande, é procedido em separado do serviço de coleta domiciliar.

\section{Indicador de Drenagem Urbana}

Um dos mais preocupantes problemas detectados relativamente a esse indicador diz respeito à ocorrência de inundação em via pública. As duas hipóteses mais prováveis para essa inundação são a ocorrência de falha no projeto, ou a má execução dos serviços de pavimentação.

Acostumada a conviver com os imbróglios advindos das chuvas que caem sobre a região, a população fomentava a perspectiva de uma redução significativa dos problemas a partir da conclusão dos serviços de urbanização. A inexistência de pavimentação em algumas áreas da poligonal urbanizada se constitui em uma evidente constatação de falha na implementação do projeto. Deve ser registrado que a inspiração do projeto de urbanização decorreu dos constantes alagamentos que fustigavam a área urbanizada. Assim, quase 22\% dos moradores imputaram a drenagem como precária ou péssima, e tão somente 3,33\% avaliaram como boa.

A análise decorrente das formulações advindas do questionário, do ponto de vista da insuficiência da salubridade, coincide com a dos usuários, enquanto os resultados indicam que 78,33\% da área é salubre na perspectiva da drenagem urbana.

\section{Indicador Socioeconômico e Cultural}

Os resultados obtidos para esse indicador apresentaram a pior performance de salubridade ambiental entre todos os indicadores considerados, enquadrando-se 56,67\% das unidades habitacionais como insuficientemente salubres.

Praticamente $25 \%$ dos(as) chefes de família percebem menos que meio salário mínimo. A renda familiar não ultrapassou o patamar de 3 salários mínimos em nenhuma moradia. Tem-se bastante claro que a maioria da população é extremamente carente, com óbvios impedimentos de realizar procedimentos que contribuam para uma satisfatória performance da salubridade ambiental, sobretudo no que concerne à efetivação de melhorias nas unidades habitacionais. 
Nenhum dos(as) chefes de família tem curso superior (completo ou mesmo incompleto), apenas $26,67 \%$ têm o ensino médio completo, $8,33 \%$ são analfabetos, e o restante possui algum grau de escolaridade. Esses índices ocasionam um agravante quanto à implementação de programas ambientais. Uma política pública que privilegie a educação, aumentado o grau de escolaridade da população, redundará em um incremento nas possibilidades, não só de compreensão, mas também de engajamento nas questões inerentes ao saneamento ambiental.

Especificamente nesse projeto de urbanização, faz-se sentir a necessidade da implementação do instrumento da regularização fundiária, já que $100 \%$ das moradias não detêm escritura pública. A imissão da posse implica em uma condição permanente de segurança aos moradores, constituindo uma condição para a efetivação de alguns direitos constitucionais, a exemplo do lazer, do trabalho, da educação e da saúde. Caso a regularização fundiária estivesse conclusa, o nível de salubridade teria uma significativa alteração, reduzindo praticamente à metade o nível da salubridade insuficiente.

\section{Indicador de Condições de Moradia}

Esse indicador apresentou o segundo pior resultado quanto à salubridade ambiental, com forte influência do estado de conservação das unidades habitacionais, já que no aspecto relativo à tipologia construtiva as moradias habitacionais apresentam boas condições estruturais, sobretudo no tocante à estrutura de fechamento e de cobertura, uma vez que contempladas por materiais duráveis, predominantemente alvenaria de tijolos e telha cerâmica.

No aspecto da conservação das unidades habitacionais, os resultados apontaram que $26,67 \%$ das unidades foram classificadas como precárias e péssimas, e 45\%, como ótimas ou boas. Em razão de o nível de renda dos moradores ser baixo, essa configuração tem uma tendência natural de apresentar, ao longo do tempo, um resultado mais desfavorável, agravado pela não efetivação da regularização fundiária, que inibe investimentos dos "proprietários" das unidades habitacionais.

\section{Indicador de Controle de Vetores}

As informações quanto à ocorrência de doenças transmitidas por vetores (dengue, febre amarela, doença de chagas, leishmaniose e esquistossomose) foram obtidas a partir da Unidade Básica de Saúde da Família localizada na comunidade.

Não foi manifestado absolutamente nenhum caso de doença transmitida por vetores no período compreendido entre junho de 2013 e junho de 2014. Portanto, sob esse aspecto, a área urbanizada é considerada 100\% salubre.

Cabe registrar que existe uma dependência da Unidade Básica de Saúde da Família em relação à rede hospitalar privada no que concerne à prestação de informações sobre o acometimento de enfermidades. De acordo com o responsável pela unidade, nem sempre essas informações são repassadas. Embora exista o acompanhamento por parte dos agentes de saúde, pode acontecer, fortuitamente, que tenha ocorrido algum caso das doenças supracitadas, que foram tratadas na rede particular, e não tenha havido o conveniente repasse da informação que, sublinhe-se, é obrigatório. Portanto, essa excepcional salubridade pode não espelhar, verdadeiramente, a realidade desse indicador.

\section{Índice de Salubridade Ambiental da comunidade Novo Horizonte}

Em função da metodologia proposta, que considera a integralidade dos indicadores analisados acima, foi determinado que a área urbanizada apresenta os seguintes níveis de salubridade: $43,33 \%$ da área foi classificada como salubre, $46,67 \%$ foi enquadrada como de salubridade moderada, e $10 \%$ foi considerada como salubridade insuficiente (Figura 3).

Esses números mostram, inequivocamente, que o nível de salubridade ambiental da comunidade urbanizada é aceitável, mas também indicam que a diminuição, ou mesmo eliminação, do índice de salubridade insuficiente deve ser buscada, sobretudo por parte do poder público constituído, acompanhado da participação dos moradores da comunidade - ou de sua representação.

É por demais importante que se analise individualmente os resultados de cada um dos diversos indicadores, sob pena de que se cometa uma avaliação equivocada ou distorcida. Como pode ser observado, houve indicadores cuja performance recomenda procedimentos que elevem o seu índice de salubridade, sobretudo, no caso dessa pesquisa, dos indicadores socioeconômico e cultural, e de condições de moradia.

\section{Comparação dos diversos cenários de urbanização}

Os resultados referentes ao Índice de Salubridade Ambiental para a comunidade Novo Horizonte, na perspectiva dos cenários propostos na metodologia, estão detalhados na Tabela 2. Eles foram obtidos de forma análoga ao cenário geral, considerando os mesmos indicadores e subindicadores.

Percebe-se que entre os cenários desenhados a situação mais desfavorável é em relação às melhorias habitacionais, enquanto praticamente não ocorreram diferenças significativas entre o cenário composto pelas habitações preservadas e o cenário formado pelas casas tipo padrão.

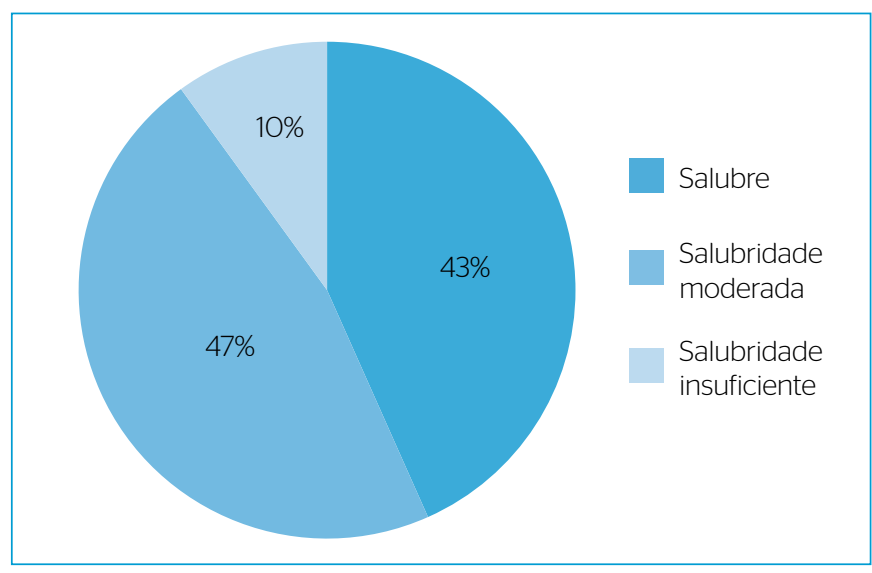

Figura 3 - Índice de salubridade ambiental da comunidade Novo Horizonte. 
Os indicadores socioeconômicos e culturais, e de condições de moradia, foram os que mais contribuíram para essa desfavorabilidade em favor das melhorias. Embora os cenários formados pelas casas tipo padrão e habitações preservadas, também, tenham apresentado um baixo índice relativamente ao indicador socioeconômico e cultural, eles mostraram um desempenho bem melhor quanto ao indicador condições de moradia.

Fica, indubitavelmente, claro que, no caso específico das melhorias, o resultado teria sido mais favorável caso o indicador de condições de moradia tivesse apresentado melhores performances nos seus diversos subindicadores, especialmente quanto à conservação da moradia habitacional.

Os cenários formados pelas habitações preservadas e pelas casas tipo padrão apresentaram resultados bem próximos aos do cenário geral. Houve claramente um avanço na salubridade ambiental da área urbanizada em relação à situação pré-urbanização, como evidencia a Figura 4.

\section{CONCLUSÃO}

O desenvolvimento desta pesquisa oportunizou demonstrar a necessidade da efetivação de avaliação pós-ocupacional nos projetos de urbanização para verificar a eficácia dos empreendimentos, sobretudo com foco na melhoria da qualidade de vida desses ambientes construídos, sob o viés do saneamento ambiental.

A metodologia proposta permitiu alcançar resultados que se contrapõem ao que é efusivamente decantado por alguns gestores públicos, ou seja, a urbanização da comunidade Novo Horizonte não se fez acontecer na amplitude desejada. Essa constatação é preocupante justamente porque a urbanização envolveu um volume considerável de recursos públicos, que não foram suficientes para atingir integralmente os objetivos propostos, uma vez que $10 \%$ da população vive, ainda, sob uma condição de insalubridade ambiental.

Esta pesquisa constatou a necessidade imperiosa de investimentos na área social. Em todos os cenários analisados, os indicadores que têm estreita relação com a temática social foram os que apresentaram os piores resultados. Em que pese os diversos programas sociais ofertados pelo governo federal terem atenuado a condição de extrema pobreza dos moradores periféricos, urge a efetivação de políticas públicas que ofertem à população condições permanentes de melhoria social, econômica e cultural. Esses investimentos acarretarão, indubitavelmente, uma otimização da salubridade ambiental na comunidade urbanizada.

Houve um destaque diferenciado quanto aos aspectos de abastecimento de água e resíduos sólidos. Sobre eles não foi identificado - considerando o cenário geral da urbanização - nenhum episódio de salubridade insuficiente. Sob o ponto de vista de satisfação dos moradores, esses indicadores também foram os que mais se destacaram positivamente.

Considerando que o indicador de drenagem urbana não obteve uma conceituação aceitável para uma obra recém-entregue, ele poderia ter sido mais bem avaliado caso a urbanização dos bairros do entorno
Tabela 2 - Nível de salubridade ambiental para os cenários propostos.

\begin{tabular}{l|c|c|c}
\multirow{2}{*}{ Índice de salubridade (\%) } & \multicolumn{3}{|c}{ Cenário } \\
\cline { 2 - 4 } & $\begin{array}{c}\text { Habitação } \\
\text { preservada }\end{array}$ & $\begin{array}{c}\text { Melhoria } \\
\text { habitacional }\end{array}$ & Casa-padrão \\
\hline Salubre & 47,37 & 23,26 & 42,86 \\
\hline Salubridade moderada & 47,37 & 62,79 & 51,43 \\
\hline Salubridade insuficiente & 5,26 & 13,95 & 5,71 \\
\hline
\end{tabular}

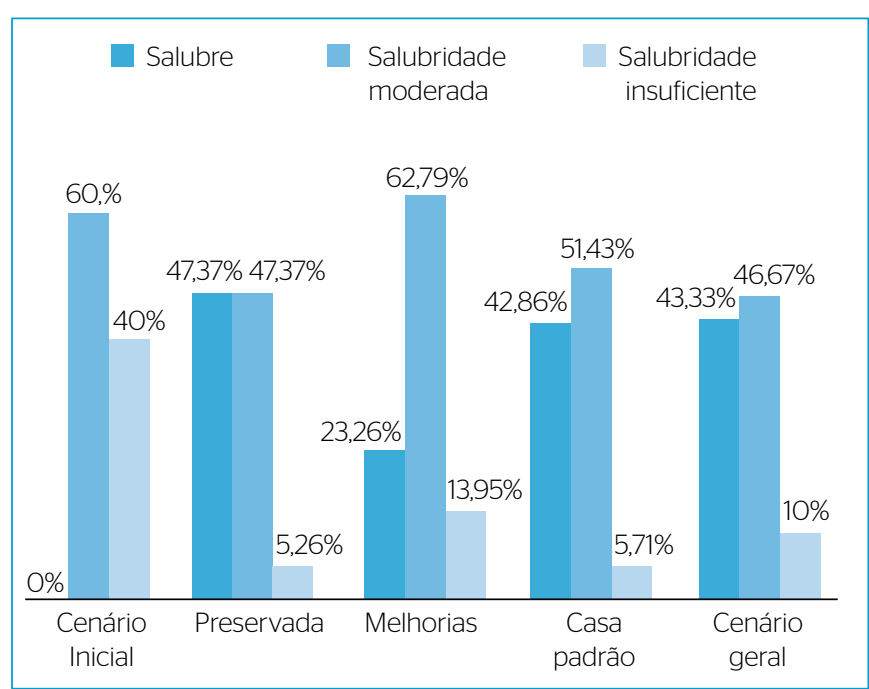

Figura 4 - Nível de salubridade ambiental nos diversos cenários propostos para a área urbanizada.

tivesse ocorrido, uma vez que o fluxo das águas da sub-bacia hidrográfica converge para a área urbanizada.

Foi identificado o quão nefasta é a execução de uma obra de urbanização segmentada no tempo, sobretudo quando os serviços de esgotamento sanitário são realizados em um primeiro instante. No caso particular, o não acompanhamento da obra de esgotamento pela concessionária dos serviços redundou em problemas que persistem há mais de três anos e, pior, sem uma perspectiva de solução em curto prazo.

Os resultados indicaram, dentre os cenários avaliados, que a salubridade ambiental das unidades habitacionais que sofreram intervenções físicas de melhorias ficou aquém do esperado, certamente por conta da singeleza dessas ações. É necessário que se persiga uma solução que contemple, de fato, uma melhoria substancial nas edificações.

As unidades habitacionais tipo padrão poderiam ter se destacado, do ponto de vista da salubridade ambiental, entre os cenários, o que não veio a ocorrer. Os resultados pouco diferem das unidades que não passaram por intervenção física oficial.

\section{AGRADECIMENTO}

Este artigo foi desenvolvido no âmbito do Projeto Bramar, financiado pela FINEP/CTHIDRO e também teve o apoio do CNPq. 


\section{REFERÊNCIAS}

ALMEIDA, M.A.P. (1999) Indicadores de salubridade ambiental em favelas urbanizadas: o caso de favelas em áreas de proteção ambiental. 226f. Tese (Doutorado em Engenharia de Construção Civil e Urbana) Universidade de São Paulo, São Paulo.

BATISTA, M.E.M. (2005) Desenvolvimento de um sistema de apoio à decisão para a gestão urbana baseado em indicadores ambientais. Dissertação de Mestrado - Universidade Federal da Paraíba, João Pessoa.

BORJA, P.C. (2014) Política pública de saneamento básico: uma análise da recente experiência brasileira. Saúde e Sociedade, São Paulo, v. 23, n. 2, p. $432-447$.

BRASIL. (1997) Lei no 9.433, de 8 de janeiro de 1997. Institui a Política Nacional de Recursos Hídricos e cria o Sistema Nacional de Gerenciamento de Recursos Hídricos. Brasília: DOU.

BRASIL. (2007) Lei no 11.445, de 5 de janeiro de 2007. Estabelece diretrizes nacionais para o saneamento básico e dá outras providências. Brasília: DOU.

BRASIL. Ministério da Saúde. (2004) Organização Pan-Americana da Saúde. Avaliação de impacto na saúde das ações de saneamento: marco conceitual e estratégia metodológica. Organização PanAmericana da Saúde. - Brasília: Ministério da Saúde. 116 p

DIAS, M.C. (2003) Índice de salubridade ambiental em áreas de ocupação espontânea: estudo em Salvador, Bahia. Dissertação de Mestrado - Universidade Federal da Bahia, Salvador.

JORDÃO, E.P.; PESSÔA, C.A. (2009) Tratamento de Esgotos Domésticos. 5 ed. ABES: Rio de Janeiro.

KOWALTOWSKI, D.C.K:; GRANJA, A.D; MOREIRA, D.C. (2O13) Métodos e instrumentos de avaliação de projetos destinados à habitação de interesse social. In: VILLA, S.B;; ORNSTEIN, S.W. Qualidade Ambiental na habitação: avaliação pós-ocupação. 1. Ed. São Paulo: Oficina de Textos. Cap. 7, p. 149-184

LIBÂNIO, P.A.C.; CHERNICHARO, C.A.L.; NASCIMENTO, N.O. (2005) A dimensão da qualidade de água: avaliação da relação entre indicadores sociais, de disponibilidade hídrica, de saneamento e de saúde pública. Revista Engenharia Sanitária e Ambiental, v. 10, n. 3, p. 219-228.

LIMA, M.L.C.C.; SOMEKH, N. (2013) Análise urbanística e diagnóstico de assentamentos precários: um roteiro metodológico. Ambiente Construído, Porto Alegre, v. 13, n. 1, p. 109-127.

MARICATO, E. (2011) O impasse da política urbana no Brasil. Petrópolis, RJ: Vozes

MARTINS, G.A. (2002) Estatística Geral e Aplicada. São Paulo: Atlas.

MENEZES, G.O. (2007) Aplicação do Índice de Salubridade Ambiental em Comunidades Carentes e sua Comparação com Comunidades
Padrão: Instrumento para Planos de Gestão Municipal. Dissertação de Mestrado - Universidade Federal de Ouro Preto, Ouro Preto.

NUNES, M.F.O;; CARISSIMI, M. (2011) Matriz de Indicadores para Avaliação Pós-Ocupação. In: 20 Simpósio Brasileiro de Qualidade do Projeto no Ambiente Construído. Rio de Janeiro, p. 235-244

ORNSTEIN, S.W.; ROMERO, M.A. (1992) Avaliação pós-ocupação do ambiente construído. São Paulo: Estúdio Nobel e Edusp.

PATEL, K. (2013) A successful slum upgrade in Durban: A case of formal change and informal continuity. Habitat International, v. 40, p. 211-217.

REGO, J.C.; GALVÃO, C.O.; VIEIRA, Z.M.C.L.; RIBEIRO, M.M.R.; ALBUQUERQUE, J.P.T.; SOUZA, J.A. (2013) Atribuições e responsabilidades na gestão dos recursos hídricos - o caso do açude epitácio pessoa/boqueirão no cariri paraibano. In: Anais do XX Simpósio Brasileiro de Recursos Hídricos. Bento Gonçalves.

ROMERO, M.A.; VIANNA, N.S. (2002) Procedimentos metodológicos para aplicação de avaliação pós-ocupação em conjuntos habitacionais para a população de baixa renda: do desenho urbano à unidade habitacional. In: ABIKO, K.A; ORNSTEIN, S.W. Inserção urbana e avaliação pós-ocupação (APO) da habitação de interesse social. São Paulo: FAUUSP (Coletânea Habitare/FINEP,1). 373p.

SANTOS, E.C. (2013) Avaliação dos níveis de salubridade em edificações multifamiliares de interesse social na cidade de Campina Grande - PB. Dissertação de Mestrado - Universidade Federal de Campina Grande, Campina Grande.

SANTOS, J.F. (2009) O saneamento como instrumento de promoção da saúde. In: Brasil. Ministério das Cidades. Secretaria Nacional de Saneamento Ambiental. Programa de Modernização do Setor Saneamento (PMSS). Conceitos, características e interfaces dos serviços públicos de saneamento básico/coord. Berenice de Souza Cordeiro. Brasília: Editora, v. 2. 193p.

SENRA, J.B.; MONTENEGRO, L.R. (2009) Recursos hídricos e saneamento: integrar pra avançar na gestão e implementação das políticas. In: Brasil. Ministério das Cidades. Secretaria Nacional de Saneamento Ambiental. Programa de Modernização do Setor Saneamento (PMSS). Conceitos, características e interfaces dos serviços públicos de saneamento básico/coord. Berenice de Souza Cordeiro. Brasília: Editora, v. 2. 193p.

VALLADARES, A. (2013) The Community Architect Program: Implementing participation-in-design to improve housing conditions in Cuba. Habitat International, v. 38, p. 18-24.

VOORDT, D.J.M.V.D; WEGEN, H.B.R. (2005) Architecture in use: an introduction to the programming, design and evaluation of buildings. Oxford: Architetural Press. 237 p. 